\title{
Methodology for determining rom size distribution
}

http://dx.doi.org/10.1590/0370-44672014670184

\section{Christiane Ribeiro da Silva}

Federal University of Rio Grande do Sul (UFRGS) Porto Alegre - Rio Grande do Sul - Brazil chribeiro.s@gmail.com

\section{Vládia C. G. de Souza}

Federal University of Rio Grande do Sul (UFRGS) Porto Alegre - Rio Grande do Sul - Brazil vladiasouza@gmail.com

\section{Jair C. Koppe}

Federal University of Rio Grande do Sul (UFRGS) Porto Alegre - Rio Grande do Sul - Brazil jkoppe@ufrgs.br

\section{Metodologia para determinação de curva granulométrica de rom}

\begin{abstract}
A methodology to determine the size distribution curve of the ROM was developed in a Brazilian iron ore mine. The size of the larger fragments was determined taking photographs and setting the scale of the images to analyze their dimensions (length of their edges and areas). This was implemented according to a specific protocol of sampling that involves split and homogenization stages in situ of a considerable quantity of ore (about 259 metric tonnes). During the sampling process, larger fragments were separated and smaller size material was screened. The methodology was developed initially in order to preview the performance of a primary gyratory crusher that is fed directly from trucks. Operational conditions of the equipment such as closed and open-side settings could be adjusted previously, obtaining different product size distributions. Variability of size of the fragments affects subsequent stages of crushing and can increase circulating load in the circuit. This leads to a decrease of productivity or recovery of the ore dressing. The results showed insignificant errors of accuracy and reproducibility of the sampling protocol when applied to friable itabirite rocks.
\end{abstract}

Keywords: sampling; quality control; crushing, image analyses.

\section{Resumo}

A metodologia para determinar a curva granulométrica de ROM foi desenvolvida em uma mina de ferro localizada no Brasil. O tamanho dos blocos maiores foi determinado a partir de fotografias, por meio das quais foi definida uma escala para analisar as dimensões dos blocos (comprimento e área). Isso foi implementado de acordo com um protocolo de amostragem específico, que envolve etapas de divisão $e$ de homogeneização in situ de uma considerável quantidade de minério (cerca de 259 toneladas). Durante o processo de amostragem, os blocos maiores foram segregados, para mensuração, por análise de imagens, enquanto que os de menor tamanho foram peneirados. A metodologia foi desenvolvida para avaliar, inicialmente, o desempenho de um britador giratório, alimentado por basculamento direto, a partir de caminhões. Condições operacionais desse tipo de equipamento, tais como configurações das aberturas de posição aberta (APA) e de posição fechada (APF), podem ser ajustadas previamente, permitindo, assim, a obtenção de diferentes distribuições de tamanho de produto. A variabilidade de tamanho dos fragmentos afeta diretamente os estágios seguintes de britagem, podendo causar um aumento significativo na carga circulante do circuito. Isto leva a uma diminuição da produtividade e recuperação nas etapas posteriores. Os resultados de granulometria de ROM mostraram erros de reprodutibilidade e viés desprezíveis para o protocolo de amostragem desenvolvido, aplicado em itabirito friável.

Palavras-chave: amostragem; controle de qualidade; britagem; análises por imagem. 


\section{Introduction}

According to Chaves \& Peres, 2003 [1], comminution is a size reduction process in order to release mineral grains with economic value and concentrate them during subsequent stages of the ore dressing. This process must result in a specific range of size, which is ideal to maintain or increase the recovery of these minerals. Excessive reduction of the size of fragments generally reduces recovery and can increase consumption of reagents during the concentration process. By contrast, coarser fragments can increase the circulating load in comminution circuits, reducing also the productivity/recovery of the concentration plant. This also has implications such as the wear of certain equipment parts, load capacity of trucks and conveyor belts. The size reduction ratio is related to the breakage strength of the ore (energy specific consumption: $\mathrm{kWh} / \mathrm{t}$ ), physical and operational conditions of the screens, crushers and mills, design of the comminution circuit, blasting and mining sequence planning. Therefore all the stages of the productivity chain are connected to the size distribution of the ROM.

According to Gy, 1982 [2], the best sampling design (protocol) must be applied in order to achieve the representativeness of the material. This means it is important to know the bias and precision of the measured parameter (mineral content or size fragment) to validate the data (Gy, 1957 [3]). Sampling errors due to the heterogeneity of the ore could be decreased by collecting larger amounts of mass proportional to the cube of the top size of the fragments, since these errors that are related to the split and homogenization stages of the protocol have been minimized. Any protocol considers that there will be a reduction of the amount of mass of the samples during its implementation. The most important task is to determine the magnitude of the errors introduced when the mass amount is reduced in function of the top size of the fragments. The total error must be acceptable according to a specific purpose and confidence interval.

Minnitt, 2007 [4] and Pittard, 1993 [5] have analyzed the nature of the errors and how these can contribute to the total sampling error regarding the formulas proposed by Gy and several other protocols developed for the mining industry. According to these protocols, it would be necessary to collect very large amounts of samples of the material that feeds the crushers (especially primary crushers) or semi-autogenous mills. This would be possible only on stopped conveyor belts. Napier-Munn et al., 1996 [6] suggested to pick up the fragments from the stopped conveyor belt and classify them manually by sieve frames. Either way, there would still be some doubt about the representativeness of this kind of sampling as related to the mass of a truckload, a day of Run-of-Mine-Production, a year or a whole deposit. Pittard, 1993 [5] suggested several times that when circumstances are such that it is impossible to collect a larger mass amount, it is better to collect smaller amounts in different occasions, increasing the increment number. This could be more practical and representative in order to preview performance of the ore dressing and the mining sequence and the origin of the samples from the deposit.

If it were possible to determine the size of very large fragments by practical means, it would be possible to model and simulate primary crushers or semi-autogenous mills more accurately. According to King, 2001 [7], modeling is a mathematical representation of the equipment in order to improve their performances. Primary crushers usually receive feed that contains only small amounts of material that is smaller than the open-side set of the crusher. Therefore, almost all fed material is crushed in the machine. King, 2001 [7] asserts that the size distribution of the material in the product is independent of the size distribution in the feed and is a function primarily of the opening setting of the crusher and to a lesser extent of the nature of the material that is crushed. The developed methodology in this study intends also to verify if this is always true to "the case". This means that it was necessary firstly to analyze size distribution of the ROM, which is a more difficult task. The next work will be to determine the size of the products coming from the primary gyratory crushers. The subsequent stages of crushing could be analyzed collecting material on stopped conveyor belts or making a video recording of the fragments on them to determine their size by image analysis.

Thus to develop this methodology, there were two options: (i) to increase the increment number (the number of samples on stopped conveyor belt, for example, along one year) or (ii) to sample the ROM step by step (according to the several stages of split and homogenization) in situ. The last option was chosen because the ROM feeds directly onto primary crusher in this mine. Very large fragments could not be screened. Therefore, they were photographed beside an object with a known area/diameter (like a ball with $20 \mathrm{~cm}$ of diameter). The known object is used to scale and measure areas of the fragments. This methodology is more practical compared to manual collecting on a stopped conveyor belt and allows that a larger mass be sampled.

In this mine, after a third, fourth or fifth crushing stage in conic crushers, the final product must be smaller than $32 \mathrm{~mm}$. The primary crusher is gyratory (89"x69") and it has a gape of about 2 meters. The gape determines the maximum size of material that can be accepted. Primary crushers are designed so that the maximum size that can be presented to the crusher is approximately $80 \%$ of the gape. The primary operating variable available on a crusher is the set and on gyratory the open-side set (OSS) is specified. This reflects the fact that considerable portions of the processed material fall through the crusher at OSS and this determines the characteristic size of the product. The set of a crusher can be varied in the field and some crushers are equipped with automatically controlled actuators for the control of the set. However, the set of gyratory and jaw crushers is not customarily changed during operation except to compensate for wear on the machine. The capacity is a function of size and OSS. The studied primary crusher has OSS and CSS (close-side-set) equal to $20 \mathrm{~cm}$ and $14 \mathrm{~cm}$ respectively and processes about 4.000 tonnes per hour.

\section{Methodology}

The methodology was implemented through several steps of split and homogenization on a ROM pile taken from a workbench classified as friable itabirite (FI). Ore was loaded into a truck in which balance weight showed 
a total mass about 259 tonnes. The ore was dumped in a proper and signalized place, thus adopting the best safety rules of the mining company.

The minimum staff to perform the work consisted of four people: two were responsible for implementation of the sampling protocol, one for monitoring visual and audible signs of danger and one for operating a backhoe loader. Three days were enough to complete the sampling work in situ.

The backhoe loader spread the dumped ore pile, picking up larger rock block (about $50 \mathrm{~cm}$ or larger). Each large rock block was disposed in a row and beside it was put an object (like a ball with a $20 \mathrm{~cm}$ of diameter) to photograph

Figure 1

ROM being dumped (a) and larger blocks (BM1) being photographed (b).

The remaining pile separated from the larger blocks was denominated "original pile". This original pile was flattened and demarcated to be divided into "four pieces" (Figure 2 (a)).

Each one was homogenized separately, originating piles with approxi-

Figure 2

Demarcation (a) and homogenization and splitting process (b).

A detailed sampling flowchart can

Figure 3

Sampling flowchart of the ROM showing the mass reduction ratio. them individually. Remaining material was spread becoming a flattened pile, homogenized and split into consecutively smaller piles and similar to procedures performed in the laboratory.

When the division process was finished, fragments between $2.5 \mathrm{~cm}$ and $50 \mathrm{~cm}$ were found and disposed in a line near the last two little piles. From these last two piles, the material was screened.

Figure 1(a) shows friable itabirite ROM being dumped at the beginning of the sampling process. After, the larger rock blocks were segregated by a backhoe loader. This was done by spreading the material of the pile along its edges and flattening it gradually.
Figure 1 (b) shows some of the larger blocks being photographed.

After field procedures, each large rock block was measured, analyzing its major dimensions and areas by free software (Fiji).

Firstly, each image is open and a line is drawn on the reference object to scale the objects of the image (blocks or ore fragments). Some ore blocks were measured in loco to verify their measurements given by the software posteriorly.

After the setting of the scale, lines along the edges of a block are drawn and so applying the command "analyze>measure" a table is generated with the recorded measurements.

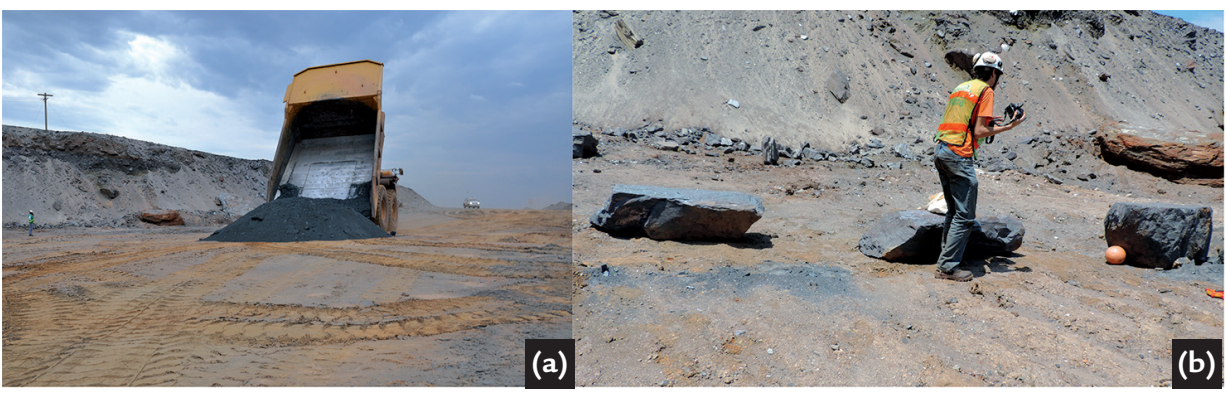

mately $1 / 4$ of the mass of the original pile (Figure 2 (b)). From the former four piles, opposite diagonally two were homogenized and flattening once more.

These two new piles were divided successively, reaching a maximum reduction ratio equivalent to $1 / 32$ of the total mass of the original pile.

Finally, the material of the last two piles (considered "twins") was totally classified in order to determine their size distribution curves and verify their differences (reproducibility checking).

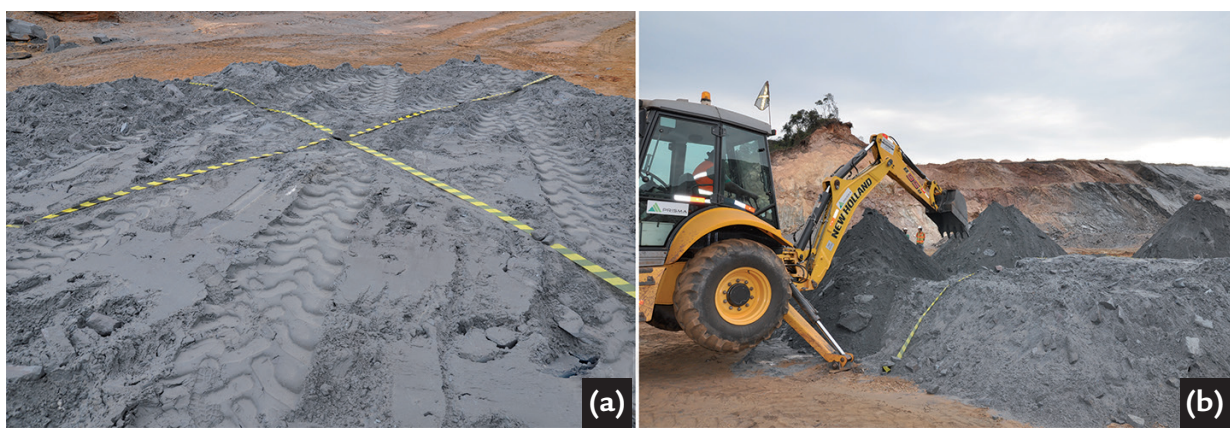

be observed in Figure 3.

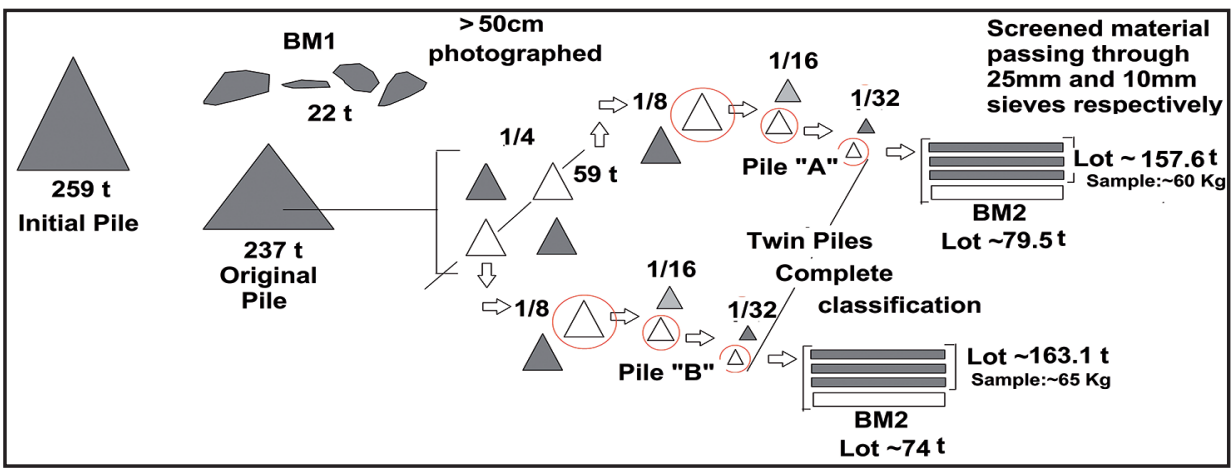


Initially there is a pile dumped by the truck. From this pile, larger rock blocks (BM1) are segregated generating the "original pile". This is divided to generate four piles. From these, two diagonally opposite piles are subjected to homogenization and flattening. Then these two piles are successively divided three times. The material from the last two piles is completely classified. This was made from dumping material directly by backhoe loader into
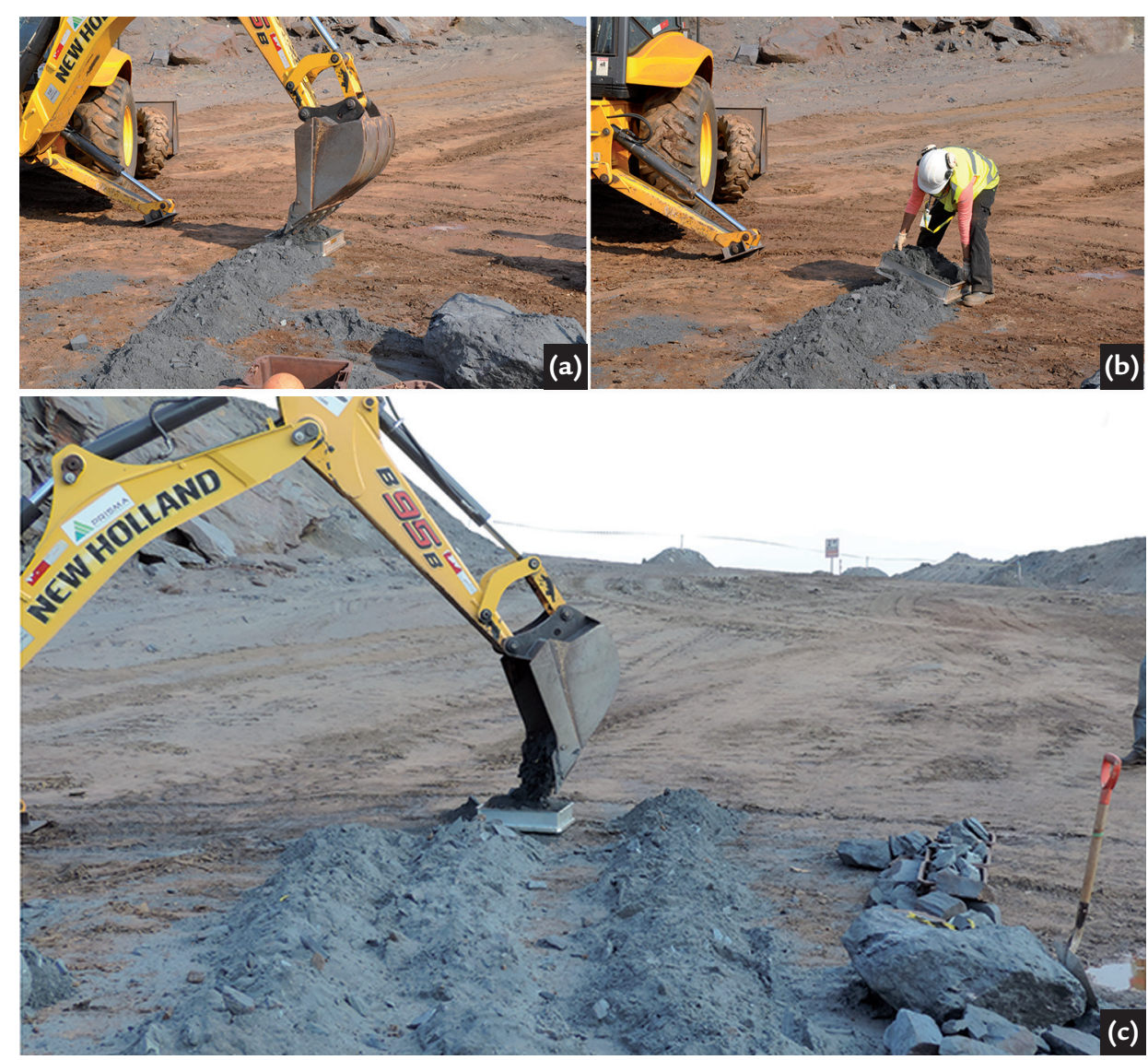

The ore disposed along the rows smaller than $25 \mathrm{~mm}$ was screened again into a $10 \mathrm{~mm}$ sieve. Practically all the material was passing in $10 \mathrm{~mm}$. About $60 \mathrm{~kg}$ and $65 \mathrm{~kg}$ were collected from the last two piles ("twin piles") respectively denominated "pile A" and "pile B". These samples were stored in four double plastic

bags (two per pile) identified by the source code, collecting date and workbench number. The samples were sent to a nearby laboratory in order to determine the size of the fragments smaller than $10 \mathrm{~mm}$. In the laboratory, homogenization was carried out in a rotary splitter and the material was classified by a sieve series with 6.3 schedule through the several steps of homogenization and split in situ.

Figure $4(a, b)$ illustrates the formation process of the rows containing ore fragments smaller than $25 \mathrm{~mm}$ while the larger fragments retained on the screen were manually picked up or pushed by the backhoe loader to a near site. Figure 4 (c) shows the final disposal of the three rows containing $10 \mathrm{~mm}$ passing material and a fourth with the larger fragments (BM2).
Figure 4

Classification and

formation process of the rows.

mm up to $45 \mu \mathrm{m}$ openings.

The fragments larger than $2.5 \mathrm{~cm}$ (BM2) in the fourth row were photographed beside a scale bar with black and yellow $20 \mathrm{~cm}$ bands. The fragments were measured, setting the scale of the images and designing a polyline around each one and recording its area.

\section{Results}

After dumping of the material and separation of the larger blocks, each one was measured by Fiji and classified according to a square sieve series with openings from 160 up to $40 \mathrm{~cm}$. The total number of fragments was recorded. In this case by photograph were recorded 22 rock blocks larger than about $50 \mathrm{~cm}$ (BM1) which were separated in the initial stage of the sampling protocol. The results can be seen in Table 1. During the splitting and homogenization final stages of the sampling protocol, the material (BM2) in the fourth row was classified according to a square sieve series with openings from 40 up to $2.5 \mathrm{~cm}$. These results can also be seen in Table 1 .

The number and size of the fragments found in the fourth row beside each twin pile were very similar. The same occurred to the size distribution of the fragments analyzed in laboratory by screening (Tables 2 and 3 ).

So, it was concluded that the errors of division and homogenization, especially of the larger fragments for this kind of ore (friable itabirite) were negligible during implementation of the sampling protocol. 
Table 1

Results of the classification by size of large rock fragments

Samples with about $30 \mathrm{~kg}$ were analyzed separately in the laboratory: two with about $30 \mathrm{~kg}$ came from the pile "A" and two came from pile "B" (the last two piles or "twin" piles). Therefore, reproducibility inside the pile and between the "twin" piles A and B

\begin{tabular}{|c|c|c|c|c|c|}
\hline & \multicolumn{3}{|c|}{ Sieve opening $(\mathrm{cm})$} & & \\
\hline COD & Passing & Retained & Average Size & $\begin{array}{l}\text { Number of } \\
\text { Blocks }\end{array}$ & Volume $\left(\mathrm{m}^{3}\right)$ \\
\hline BM1 & 160 & 80 & 120 & 2 & 3.0720 \\
\hline BM1 & 100 & 60 & 80 & 2 & 0.9600 \\
\hline BM1 & 80 & 40 & 60 & 16 & 3.0720 \\
\hline BM1 & 60 & 40 & 50 & 1 & 0.1200 \\
\hline BM1 & 50 & 40 & 45 & 1 & 0.0900 \\
\hline BM2 & 40 & 20 & 30 & 22 & 0.5280 \\
\hline BM2 & 20 & 10 & 15 & 82 & 0.2460 \\
\hline BM2 & 10 & 5 & 7.5 & 140 & 0.0525 \\
\hline BM2 & 5.00 & 2.50 & 3.75 & 35 & 0.0016 \\
\hline
\end{tabular}

could be determined (Table 3).

Granulometric analyses in laboratory are made based on the retained mass between two consecutive screens from a Tyler series. In order to combine the results from the sampling in situ and those obtained from the laboratory, it was necessary to adopt a formula for converting measurements to volume and afterwards to mass.

Hence, firstly following formula was applied to convert the results of classification by size made after analysis of the images to a volume:

Volume $=\mathrm{SS} \times \mathrm{IS} \times[(\mathrm{SS}+\mathrm{IS}) / 2] \times \mathrm{N}$, for a specific size class.

Thus, volume is the smaller size than an equivalent opening of a square screen (superior screen=SS) $\mathrm{x}$ larger size than an equivalent opening of a square screen (inferior screen=IS) $\mathrm{x}$ arithmetic average size of the superior and inferior equivalent screens $(\mathrm{AS}=[(\mathrm{SS}+\mathrm{IS}) / 2]) \mathrm{x}$ number of fragments passing through the superior equivalent screen and retained on the inferior one (N). For example: two larger fragments (BM1) were found and classified as $-160+80 \mathrm{~cm}$ (Table 1). They have a volume equivalent to: 160 x $80 \times((160$ $+80) / 2) \times 2=3.07 \mathrm{~m}^{3}$. Finally to convert volume to mass for a specific size class, the volume by the density number was multiplied. This last was experimentally determined previously to the blasting of the workbench.
One of the most important factors for composite results of classification by size by different techniques is fairly the conversion of the size of fragments to a volume. The density factor also has an important role, although, it is taken as a constant factor in many cases. Despite these considerations, in order to convert volume to mass, a constant value of density and equal to $3 \mathrm{t} / \mathrm{m}^{3}$ was used in this work. This value was found by collecting three chips of ore samples on the workbench face. The samples were cut as small blocks with a standard size (about 10 x 6 x $6 \mathrm{~cm}$ ) and weighted. The same method is applied to determine the conversion factor from volume to mass in the block model of this mine and estimate the mass in the planning of the mining sequence (as well as reconciliation process).

Table 2 shows the final size distribution for the materials came from the twin piles " $A$ " and " $B$ " respectively. This final size distribution resulted from the combination of the size classification of the sampling in situ with posterior measurements by image analysis and screening of the material smaller than $10 \mathrm{~mm}$ in laboratory. It represents the size distribution based on the total mass of the load truck $(259 \mathrm{t})$. In order to determine final or combined size distributions, it was assumed that final mass from each twin pile ("A" and "B") was equal 1/32 from the mass of the original pile. The mass of the original pile was assumed to be equal to 259 metric tonne (truck load) minus the mass of the larger blocks (BM1). 


\begin{tabular}{|c|c|c|c|c|c|c|c|c|}
\hline \multirow[b]{3}{*}{ COD } & \multicolumn{3}{|c|}{ Pile "A" } & \multicolumn{3}{|c|}{ Pile "B" } & & \\
\hline & \multicolumn{2}{|c|}{ Mass (tonne) } & \multirow{2}{*}{$\begin{array}{c}\% \\
\text { Cum. } \\
\text { Ret. }\end{array}$} & \multicolumn{2}{|c|}{ Mass (tonne) } & \multirow{2}{*}{$\begin{array}{c}\% \\
\text { Cum. } \\
\text { Ret. }\end{array}$} & \multicolumn{2}{|c|}{ Errors (\%) } \\
\hline & Sample & Lot & & Sample & Lot & & $\begin{array}{l}\text { Abso- } \\
\text { lute }\end{array}$ & Relative \\
\hline BM1 & 9.22 & 9.22 & 3.56 & 9.22 & 9.22 & 3.56 & 0.00 & 0.00 \\
\hline BM1 & 2.88 & 2.88 & 4.67 & 2.88 & 2.88 & 4.67 & 0.00 & 0.00 \\
\hline BM1 & 9.22 & 9.22 & 8.23 & 9.22 & 9.22 & 8.23 & 0.00 & 0.00 \\
\hline BM1 & 0.36 & 0.36 & 8.37 & 0.36 & 0.36 & 8.37 & 0.00 & 0.00 \\
\hline BM1 & 0.27 & 0.27 & 8.47 & 0.27 & 0.27 & 8.47 & 0.00 & 0.00 \\
\hline BM2 & 1.58 & 50.69 & 28.04 & 1.44 & 46.08 & 26.26 & 1.78 & 0.10 \\
\hline BM2 & 0.74 & 23.62 & 37.16 & 0.70 & 22.46 & 34.94 & 0.44 & 0.05 \\
\hline BM2 & 0.16 & 5.04 & 39.11 & 0.16 & 5.26 & 36.97 & -0.08 & -0.04 \\
\hline BM2 & 0.00 & 0.16 & 39.17 & 0.00 & 0.15 & 37.03 & 0.00 & 0.03 \\
\hline Lab & ---- & 2.60 & 40.17 & ---- & 3.83 & 38.51 & -0.48 & -0.38 \\
\hline Lab & ---- & 4.88 & 42.06 & ---- & 6.77 & 41.12 & -0.73 & -0.32 \\
\hline Lab & ---- & 6.30 & 44.49 & ---- & 7.67 & 44.08 & -0.53 & -0.20 \\
\hline Lab & ---- & 7.33 & 47.32 & ---- & 9.79 & 47.86 & -0.95 & -0.29 \\
\hline Lab & ---- & 9.85 & 51.12 & ---- & 12.64 & 52.74 & -1.08 & -0.25 \\
\hline Lab & ---- & 15.91 & 57.27 & ---- & 17.70 & 59.57 & -0.69 & -0.11 \\
\hline Lab & ---- & 19.38 & 64.75 & ---- & 20.47 & 67.47 & -0.42 & -0.05 \\
\hline Lab & ---- & $29.94 v$ & 76.31 & ---- & 28.14 & 78.34 & 0.70 & 0.06 \\
\hline Lab & ---- & 35.69 & 90.08 & ---- & 32.95 & 91.06 & 1.06 & 0.08 \\
\hline \multirow[t]{2}{*}{ Lab } & ---- & 25.68 & 100.00 & ---- & 23.16 & 100.00 & 0.97 & 0.10 \\
\hline & 24.42 & 259.00 & & 24.25 & 259.00 & Bias & 0.00 & -0.06 \\
\hline & & & & & & Precision & $\pm 2 \%$ & $\pm 1 \%$ \\
\hline
\end{tabular}

Resuming how the numbers in Tables 1 to 3 were calculated it follows that (Figure 3): (i) the sampled total mass (truckload) is equal to a lot about $259 \mathrm{t}$; (ii) the total mass of the larger blocks (BM1) separated in the initial steps is equal to $22 \mathrm{t}$ from the lot about $259 \mathrm{t}$ - this mass was determined after the measurements of the blocks by image analysis and their conversion to a volume (according to the previously presented formula) and finally to mass, applying a density value of $3 \mathrm{t} / \mathrm{m}^{3}$; (iii) the total mass of the original pile is the new lot and is equal to $259 \mathrm{t}-22$ $\mathrm{t}$, that is $237 \mathrm{t}$; (iv) the total mass of the fragments between 50 and $2.5 \mathrm{~cm}$ came from each twin pile, separated in the last steps, it was determined after measurements by image analysis, their conversion to a volume, after to a mass and finally multiplied by 32 to represent the mass of the lot equivalent to the truck load - from this, it results that
Table 2

Final size distribution curve or combined to piles "A" and "B"

the total mass of the lot $\mathrm{A}(\mathrm{BM} 2 \mathrm{~A})$ is equal to $79.5 \mathrm{t}$ and the lot $\mathrm{B}(\mathrm{BM} 2 \mathrm{~B})$ is $74 \mathrm{t}$; (v) the total mass of the material passing through $10 \mathrm{~mm}$ is related to the total mass of the truck load as being a lot equal to: $259 t-22 t-79.5 t=157.5$ $t$. The mass of the lot that originated the pile " $\mathrm{B}$ " is equal to: $259 \mathrm{t}-22 \mathrm{t}-74 \mathrm{t}$ $=163 \mathrm{t}$. For example, the mass of the lot related to the material retained on a screen with $4 \mathrm{~mm}$ opening to pile " $\mathrm{A}$ " is equal to: $(1.7 \% *$ x $157.5 \mathrm{t}) / 100=2.60 \mathrm{t}$ 
Table 3

Mass of the lots in function of the size classes related to the truck load

\section{*Example according to the laboratory result (Table 3 ).}

Tables 2 and 3 show respectively the errors (differences) between the combined size distribution curves to twin piles "A" and "B" and the retained (\% weight) from the laboratory results. Absolute differences were calculated based on the retained amount in each size class of the pile "A" minus of the pile "B". Relative differences were calculated dividing absolute differences by the average retained in each size class. The combined size distribution curves to twin piles "A" and "B" show an

\section{Conclusions}

The developed sampling protocol is laborious since it involves high rates of mass reduction. Anyway, it was possible to implement several steps of homogenization and split in situ and determine the granulometry of the ROM containing large rock blocks. The granulometric distribution curves show a wide range of size classes and high reproducibility. Two factors have contributed to the success of the protocol: the methodology itself and

\begin{tabular}{c|c|c|c|c|c|c|c|c|c|c|c|}
\multicolumn{2}{c}{} \\
\multicolumn{2}{c}{} \\
\cline { 2 - 13 }
\end{tabular}

absolute differences did not exceed the value of $\pm 2 \%$ (for the confidence interval of $100 \%$ ). Relative differences were $\pm 1 \%$. This means that the implemented sampling protocol showed a very high reproducibility. It was expected higher errors due to an expressive mass reduction ratio and application of several steps of split and homogenization in situ. It is a laborious protocol, but it can be done in three days and four people in field.

In addition, in the conversion from size to volume and mass, it is not nec- essary to verify reproducibility, which means that it is enough to compare the number of fragments by size class of the last two piles, which were very similar. On other hand, this conversion process helped to calculate the mass reduction ratio along with the implementation of the steps of the protocol. There is an error associated to each step and it would be possible in future works to analyze its implications regarding Gy's formula and constants of the heterogeneity of the materials. the fact that the heterogeneity of the friable iron ore was not so high.

Size distribution curves of the ROM are important for many reasons regarding setting of the operational and physical parameters, mainly for the primary crushers or semi-autogenous mills. In the mine, where this work was implemented, for example, the gyratory crusher has two meters of gape. The curves showed that only $5 \%$ of the material is larger than one meter. Only two blocks had a size larger than $80 \mathrm{~cm}$, the others being smaller than 1.6 meters. This means that friable itabirite ore after the blasting of the studied workbench will not damage the operation of the primary crusher.

For some specific reasons, such as structural geological characteristics of the deposit, mineralogical composition and breakage strength of the mineral grains, as well as the blasting plan, a 
large amount of very fine material was generated. Only $30 \%$ of the ROM was larger than $100 \mathrm{um}$ and $60 \%$ was smaller than $10 \mathrm{~mm}$.

Regarding a liberation size equal to $150 \mathrm{um}$, this means that $35 \%$ of the ROM could be sent directly to the flotation process regardless of other considerations, such as possibly losing smaller sized mineral grains with economic value and increase of reagents during the flotation process. Besides, this expressive amount of material smaller than $10 \mathrm{~mm}$ could be sent directly into the grinding stage that is being implemented in this mine.

It is also possible to observe that
$70 \%$ of the ROM is smaller than $20 \mathrm{~cm}$ (OSS). According to the proposed models by King to model primary crushers, it would not be possible to forecast the product granulometry. Almost all the material in fact is passing through the opening of the primary crusher. In these cases, other parameters, such as the chamber geometry, eccentricity and wear parts must be considered more relevant.

This methodology could be applied to determine size distribution of materials that are more resistant to breakage and that decrease capacity of production of the primary crushers. It could be used to improve the blasting, the load and transport systems. ROM from compact itabirite workbenches has been the target of this kind of work. They have lower content of iron, very small liberation size and can decrease significantly the productivity of the crushing stages and the recovery during the flotation process. Nevertheless, a longer time to implement the same methodology has to be considered, especially to separate the larger blocks. The precision and bias errors of this methodology compared to the mass of a workbench or the whole deposit could also be higher. Hence, it is suggested to replicate the methodology for a major number of workbenches.

\section{References}

CHAVES, A. P., PERES, A. E. C. Teoria e prática do tratamento de minérios: britagem, peneiramento e moagem ( $2^{\mathrm{a}}$ Ed.). São Paulo: Signus editora, 2003. 662p.

GY, P. M. Sampling of particulate materials: theory and practice ( $2^{\text {nd }}$ Ed.). Amsterdam: Elsevier, 1982.431p.

GY, P. M. Errors committed in size distribution. In: CONGRESS OF JAMSHEDPUR. Indian Mining J., 1957.

KING, R. P. Modeling and simulation of mineral processing systems (2nd Ed.). Butterworth-Heinemann, 2001. 403p.

MINNITT, R. C. A., RICET, P. M., SPANGENBERG, C. Part 1- Understanding the components of the fundamental sampling error: a key to good sampling practice. The Journal of the Southern African Institute of Mining and Metallurgy, v.107, p. 505-511, 2007.

NAPIER-MUNN, T. J., MORRELL, S., MORRISON, R. D., KOJOVIC, T. Mineral Comminution Circuits: Their Operation and Optimisation. Queesland, Australia: Julius Kruttschnitt Mineral Research Centre, The University of Queensland, 1996. 413 p.

PITTARD, F. F. Pierre Gy's sampling theory and sampling practice: heterogeneity, sampling correctness, and statistical process control $\left(2^{\text {nd }}\right.$ Ed.). New York: CRC PRESS, 1993. 488 p.

Received: 12 September 2014 - Accepted: 3 October 2014. 